\title{
Rapid generation of OPC-like cells from human pluripotent stem cells for treating spinal cord injury
}

\author{
Dae-Sung Kim ${ }^{1,2,3}$, Se Jung Jung ${ }^{4}$, Jae Souk Lee ${ }^{4,5}$, Bo Young Lim ${ }^{4}$, Hyun Ah Kim ${ }^{4}$, Jeong-Eun Yoo ${ }^{4,5}$, \\ Dong-Wook Kim ${ }^{4,5}$ and Joong Woo Leem ${ }^{4}$
}

Remyelination via the transplantation of oligodendrocyte precursor cells (OPCs) has been considered as a strategy to improve the locomotor deficits caused by traumatic spinal cord injury (SCI). To date, enormous efforts have been made to derive OPCs from human pluripotent stem cells (hPSCs), and significant progress in the transplantation of such cells in $\mathrm{SCl}$ animal models has been reported. The current methods generally require a long period of time ( $>2$ months) to obtain transplantable OPCs, which hampers their clinical utility for patients with SCI. Here we demonstrate a rapid and efficient method to differentiate hPSCs into neural progenitors that retain the features of OPCs (referred to as OPC-like cells). We used cell sorting to select A2B5-positive cells from hPSC-derived neural rosettes and cultured the selected cells in the presence of signaling cues, including sonic hedgehog, PDGF and insulin-like growth factor-1. This method robustly generated neural cells positive for platelet-derived growth factor receptor- $\alpha$ (PDGFR $\alpha$ ) and NG2 ( 90\%) after 4 weeks of differentiation. Behavioral tests revealed that the transplantation of the OPC-like cells into the spinal cords of rats with contusive $\mathrm{SCl}$ at the thoracic level significantly improved hindlimb locomotor function. Electrophysiological assessment revealed enhanced neural conduction through the injury site. Histological examination showed increased numbers of axon with myelination at the injury site and graft-derived myelin formation with no evidence of tumor formation. Our method provides a cell source from hPSCs that has the potential to recover motor function following SCl.

Experimental \& Molecular Medicine (2017) 49, e361; doi:10.1038/emm.2017.106; published online 28 July 2017

\section{INTRODUCTION}

Spinal cord injury (SCI) induces massive neuronal and glial cell death along with the loss of axonal connectivity and demyelination of spared axons, which result in irreversible deficits in motor and sensory functions at and below the lesion site. ${ }^{1}$ Spontaneous recovery in the injured area is limited by the intrinsic properties of the central nervous system (CNS) and by an unfavorable environment for axonal regrowth. ${ }^{2}$ There is currently no effective therapeutic option to improve functional outcomes following SCI. Potential repair strategies using cell replacement have been proposed to restore local neuronal connectivity and promote the remyelination of denuded axons. Recently, evidence has been accumulating that the transplantation of stem cells (for example, bone marrow-derived mesenchymal stem cells (reviewed in ref. 3), fetal neural stem cells (NSCs; reviewed in ref. 4), ependymal stem/progenitor cells,${ }^{5}$ and neural precursors (NPs) derived from pluripotent stem cells (PSCs ${ }^{6,7}$ ) could promote locomotor recovery. Such transplantation can be considered a promising strategy for the treatment of SCI. In particular, NPs derived from PSCs have been reported to improve locomotor function in injured animals through the partial recovery of impaired neuronal circuits or the remyelination of spared axons (reviewed in ref. 8).

When the spinal cord is injured, the loss of oligodendrocytes (ODs) and the consequent demyelination of axons contribute to the impairment of locomotor function ${ }^{9}$ and can therefore be considered therapeutic targets for cell replacement after SCI. Several reports have provided convincing evidence that the transplantation of OD precursor cells (OPCs) derived from human embryonic stem cells (hESCs) into the spinal cords of injured animals leads to axonal remyelination and functional recovery. ${ }^{7,10-14}$ Recently, a clinical trial using hESC-derived OPCs to treat SCI was attempted. ${ }^{15}$ Despite recent progress in the transplantation of hESC-derived OPCs, several critical issues remain to be solved before the method can be translated into clinical treatments for SCI. First, the current protocols

\footnotetext{
${ }^{1}$ Department of Biotechnology and BK21 PLUS project for Biotechnology, Korea University, Seoul, Republic of Korea; ${ }^{2}$ Institute of Animal Molecular Biotechnology, Korea University, Seoul, Republic of Korea; ${ }^{3}$ Department of Pediatrics, Korea University Guro Hospital, Seoul, Republic of Korea; ${ }^{4}$ Department of Physiology, Yonsei University College of Medicine, Seoul, Republic of Korea and ${ }^{5}$ BK21 PLUS project for Medical Science, Yonsei University College of Medicine, Seoul, Republic of Korea

Correspondence: Professor D-W Kim or Professor JW Leem, Department of Physiology, Yonsei University College of Medicine, 50-1 Yonsei-ro, Seodaemoon-gu, Seoul 03722, Korea.

E-mail: dwkim2@yuhs.ac or jwleem@yuhs.ac

Received 5 October 2016; revised 7 February 2017; accepted 14 February 2017
} 
for the differentiation of OPCs/ODs from hESCs consist of multiple steps and require long periods of time (at least 2 months) to derive OPCs with the potential to generate myelin sheaths after transplantation, ${ }^{16}$ increasing concerns about batch-to-batch variation in differentiation efficiency and the risk of contamination. Second, the occurrence of non-neural tissues within the grafts has been problematic, likely caused by the non-neural derivatives that can be generated along with OPCs during differentiation of hESCs. The optimal timing of cell transplantation is another issue in debate for treating SCI patients. In general, the acute phase, a stage within a few days of SCI, is generally considered not optimal for transplantation because of massive immune responses and tissue necrosis occurring. In contrast, after weeks or even months, in the chronic phase, a glial scar and inhibitory milieu that forms to protect spared tissue prohibit regeneration; thus cell transplantation may be inefficient. For these reasons, many studies using animal models have attempted to utilize the subacute phase, one to two weeks after injury, to maximize the efficacy of cell transplantation because it is a stage when acute immune responses have subsided and an inhibitory environment has not yet been established. ${ }^{8,17,18}$ Nevertheless, there is still no consensus on the optimal timing for cell transplantation in human patients; thus, further studies are required. These issues are considered major hurdles for the successful treatment of SCI by the transplantation of hESC-derived OPCs.

In an effort to overcome those technical challenges, we sought to obtain highly pure populations of NPs from hPSCs that retain the features of OPCs. To that end, cell sorting using the monoclonal antibody A2B5, which recognizes GT3 ganglioside and its O-acetylated derivatives ${ }^{19}$ (hereafter referred to as A2B5), not only enhanced the homogeneity of the derived neural cell population but also eliminated cells of other lineages as well as undifferentiated remnants from the hESC-derived neural progenies. The subsequent culture of the cells in the presence of signaling molecules favorable for OPC differentiation generated a relatively pure population of cells exhibiting OPC-like phenotypes within 4 weeks following differentiation from hPSCs. When the cells were transplanted into a subacute rat model of contusive SCI, significant locomotor recovery was observed in the hindlimbs. Immunohistochemical analyses showed that the grafts survived well in the injected site, where they differentiated into cells exhibiting the characteristic of ODs and did not form non-neural tissues or teratomas. Our simple and straight-forward approach may provide a clinically applicable cell source for treating motor dysfunction elicited by SCI.

\section{MATERIALS AND METHODS}

\section{Cell culture and generation of OPC-like cells}

hESCs (WA09, WiCell, Madison, WI, USA) and hiPSCs (MSC-iPSC, 20 a gift from Dr Daley, Harvard University) were cultured and differentiated into NPs following a method described elsewhere. ${ }^{21,22}$ Briefly, undifferentiated hPSCs were cultured with mitotically inactivated feeder cells (STO; ATCC, Manassas, VA, USA) in DMEM/F12 medium supplemented with 20\% Knock-out Serum Replacement (KSR; Invitrogen, Carlsbad, CA, USA), $1 \times$ non-essential amino acids (Invitrogen), $0.1 \mathrm{~mm} \beta$-mercaptoethanol (Sigma, St Louis, MO, USA), and $4 \mathrm{ng} \mathrm{ml}^{-1}$ basic fibroblast growth factor (bFGF; Peprotech, Rocky Hill, NJ, USA). To induce neural differentiation, hPSC colonies were lifted and cultured as embryoid bodies (EBs) in the presence of $5 \mu \mathrm{M}$ dorsomorphin (Sigma) and $5 \mu \mathrm{M}$ SB431542 (Calbiochem, San Diego, CA, USA) for 4 days and then cultivated on a Matrigel-coated (Corning, Corning, NY, USA) culture dish in $1 \times \mathrm{N} 2$-containing (Invitrogen) medium supplemented with $20 \mathrm{ng} \mathrm{ml}^{-1} \mathrm{bFGF}$ for an additional 5-7 days. Once neural rosettes appeared in the centers of attached EB colonies, they were mechanically isolated with a finely pulled Pasteur pipette and then passed onto a new Matrigel-coated culture dish after gentle trituration. The cells were expanded in N2B27 medium (composed of DMEM/F12 medium, $1 \times \mathrm{N} 2$ and $1 \times \mathrm{B} 27$ (Invitrogen)) supplemented with $20 \mathrm{ng} \mathrm{ml}^{-1} \mathrm{bFGF}$ and $20 \mathrm{ng} \mathrm{ml}^{-1}$ epidermal growth factor (EGF; Peprotech) for another week. A2B5-positive cells were isolated using Anti-A2B5-MicroBeads (Miltenyi Biotec, Bergisch Gladbach, Germany) from the expanded neural rosette cells according to the manufacturer's instructions. To induce cells with OPC-like phenotypes, the isolated A2B5-positive cells were seeded on a fibronectin-coated (Corning) culture dish at a density of $\sim 2-3 \times 10^{5}$ cells per $\mathrm{cm}^{2}$ and cultured in N2B27 medium supplemented with $10 \mathrm{ng} \mathrm{ml}^{-1}$ PDGF-AA (Peprotech), $10 \mathrm{ng} \mathrm{ml}^{-1}$ insulin-like growth factor-1, $100 \mathrm{ng} \mathrm{ml}^{-1}$ Sonic hedgehog (SHH) (R\&D Systems, McKinley Place, MN, USA), $5 \mu \mathrm{M}$ forskolin (Sigma) and $60 \mu \mathrm{g} \mathrm{ml}^{-1} \mathrm{~N}$-acetyl cysteine (NAC; Sigma) for another 7-10 days. The cells could then be cryopreserved in cryoprotectant medium (N2B27 medium: KSR: dimethyl sulfoxide $=4: 5: 1$ ) or expanded by enzymatic passaging (Accutase; Millipore, Temecular, CA, USA).

\section{Analyses by immunofluorescent staining, flow cytometry and reverse transcription polymerase chain reaction}

Cells were fixed in $4 \%$ paraformaldehyde/PBS solution for $30 \mathrm{~min}$, permeabilized with $0.1 \%$ Triton X-100/PBS (only for intracellular markers) for $10 \mathrm{~min}$, blocked with $5 \%$ normal donkey serum for $1 \mathrm{~h}$ at room temperature, and then incubated with primary antibodies at $4{ }^{\circ} \mathrm{C}$ overnight. The primary antibodies used in our study were as follows: SOX1 (1:200, Millipore), PAX6 (1:200, DSHB, Iowa City, IA, USA), Nestin (1:1000, Millipore), A2B5 (1:200, Millipore), PDGFR $\alpha$ (1:100, Santa Cruz Biotechnology, Dallas, TX, USA or 1:100, Millipore), NG2 (1:200, Millipore), and Musashi1 (1:100, R\&D Systems). After the primary antibody incubation, appropriate fluorescent secondary antibodies (Alexa-Fluor-488 or -594, Molecular Probes, Eugene, OR, USA) were used for visualization. The cells were treated with 4',6-diamidino-2-phenylindole (DAPI; Vectashield, Vector Laboratories, Burlingame, CA, USA) for $5 \mathrm{~min}$ during the staining procedure to visualize the nuclei. Cell images were captured with an Olympus IX71 microscope (Olympus, Shinjuku, Tokyo, Japan) and a DP71 digital camera (Olympus) and analyzed using Image-Pro Plus ver5.1 (Media Cybernetics, Rockville, MD, USA). For flow cytometry analysis, the cells were dissociated by incubation in Accutase (Millipore) for $5 \mathrm{~min}$ at $37^{\circ} \mathrm{C}$ and then blocked in $2 \%$ bovine serum albumin-PBS solution for $5 \mathrm{~min}$ at $4{ }^{\circ} \mathrm{C}$. The cells were bound with primary antibodies for $15 \mathrm{~min}$ at $4{ }^{\circ} \mathrm{C}$. After tagging with fluorescence-conjugated secondary antibody (Alexa-Flure-488) followed by extensive washing, the cells were analyzed using FACScan (BD Bioscience, Franklin Lakes, NJ, USA) and the Cell Quest Pro program (BD Bioscience). For reverse transcription polymerase chain reaction (RT-PCR) analysis, total RNAs were extracted using a TRIzol 
total RNA purification kit (Invitrogen). Then, $1 \mu \mathrm{g}$ of the extracted RNA was reverse transcribed using an iScript cDNA synthesis kit (Bio-Rad, Hercules, CA, USA). The cDNAs of specific genes were amplified using PowerUP SYBR master mix (Thermo Fisher Scientific, Waltham, MA, USA) in a Step One-plus real-time PCR machine (Thermo Fisher Scientific). The primer sequences and reaction conditions for the amplification of the specific genes are described in Supplementary Table 1.

\section{Spinal cord injury and cell transplantation}

Adult male rats (Sprague-Dawley, 200-225 g, Harlan Laboratories, Seoul, Korea) were anesthetized under masked-inhalation anesthesia (enflurane: induction 3\%; maintenance 2\%), and a small longitudinal skin incision and laminectomy were performed at the T9 vertebral level. The exposed dorsal surface of the spinal cord was subjected to a weight-drop impact, which was carried out by dropping a $10 \mathrm{~g}$ weight rod from a $25 \mathrm{~mm}$ height onto the cord surface using the NYU weight-drop impactor. The consistency of SCI among the animals was guaranteed by monitoring the contusion impact velocity and compression rate. The animals were warmed by radiant heat lamps during recovery from anesthesia. Manual bladder compression was performed 2-3 times per day to eliminate as much urine as possible until the animals were urinating independently. Animals that did not recover bladder function were excluded from further analysis.

One week after SCI, the rats received OPC-like cell transplantation or vehicle injection. With the rats under masked-inhalation anesthesia (enflurane: induction 3\%; maintenance 2\%), the spinal cord was re-exposed at the SCI level, and a tiny hole was opened in the dura mater over the epicenter of the injury site. The fine tip of a glass capillary $(850 \mu \mathrm{m}$ in O.D. with $100 \mu \mathrm{m}$ tip diameter) filled with OPC-like cells $\left(1 \times 10^{5}\right.$ cells per $\left.5 \mu \mathrm{l}\right)$ or PBS vehicle and connected to thin rubber tubing was inserted through the dura hole $1 \mathrm{~mm}$ from the cord surface at the injury epicenter. The OPC-like cells or PBS vehicle were administered into the spinal cord over a period of $30 \mathrm{~s}$ by blowing on the open end of the rubber tube. The capillary was left in place for $1 \mathrm{~min}$ and then slowly withdrawn to avoid any outflow of the cell suspension. The incised skin was sutured, and the animal was returned to its cage. For immune suppression, the animals received cyclosporine-A (10 $\mathrm{mg} \mathrm{kg}^{-1}$, i.p.) every day beginning on the first day prior to transplantation and continuing until the second week after transplantation. All surgeries and experiments were done with the approval of the Institutional Animal Care and Use Committee of Yonsei University College of Medicine, Seoul, Korea.

\section{Behavioral assessment}

The improvement of mobility for rats that underwent SCI followed by either OPC-like transplantation $(n=11)$ or PBS vehicle injection $(n=9)$ was examined. The animals were trained preoperatively to test locomotor functions by means of an open-field locomotor rating scale, as described by Basso, Beattie and Bresnahan (BBB), which ranged from complete paralysis $($ score $=0)$ to normal locomotion $($ score $=21) .{ }^{23}$ The rats were gently adapted to the open field, which was a molded-plastic circular enclosure with a smooth, non-slip floor ( $90 \mathrm{~cm}$ diameter, $30 \mathrm{~cm}$ wall height). Once a rat walked continuously in the open field, three blinded examiners conducted a 5-min, preoperative testing session using the $\mathrm{BBB}$ locomotor rating scale. Postoperative testing was performed on days 1, 4 and 7 after SCI and then weekly for 8 weeks after transplantation. The BBB scores collected from both hindlimbs were averaged for analysis.

\section{Electrophysiological assessment}

Myoelectric motor-evoked potentials (mMEPs) were recorded from the gastrocnemius muscle of SCI rats that received OPC-like transplantation $(n=16)$ or PBS vehicle injection $(n=9)$ to monitor the improvement of impulse conduction in the motor system. The techniques used for the stimulation, recording and electrode implantation are described elsewhere. ${ }^{24,25}$ Briefly, the rat was anesthetized with enflurane, and the head was fixed in a stereotaxic frame. A midline incision of the head skin was then made to expose the skull. Two holes (each $2 \mathrm{~mm}$ in diameter) were drilled to implant stainless-steel screws on the right side; one was positioned over the somatomotor cortex ( $2 \mathrm{~mm}$ posterior to the bregma, $2 \mathrm{~mm}$ lateral to the midline), and the other was positioned over the olfactory bulb ( $6.5 \mathrm{~mm}$ anterior to the bregma, $1 \mathrm{~mm}$ lateral to the midline). A screw ( $2 \mathrm{~mm}$ in diameter, $10 \mathrm{~mm}$ in length) was implanted and turned three times into the skull hole so that the flattened bottom end of the screw touched the cortical meninges. The exposed surface of the skull was covered with cyanoacrylic glue and dental cement to fix the screws. The skin was then sutured, leaving the screw heads exposed for use as active and reference stimulating electrodes.

The mMEPs were recorded immediately before and after SCI and on weeks 4 and 8 post transplantation. With the rats under enflurane anesthesia, the mMEPs were recorded using needle electrodes that were inserted trans-cutaneously into the left gastrocnemius muscle, with the active electrode placed into the muscle belly and the reference electrode placed near the distal tendon. To elicit mMEPs, a single square-pulse electrical stimulus $(0.2 \mathrm{~ms}$ duration, $6 \mathrm{~mA}$ intensity, $2 \mathrm{~Hz}$ interval) was delivered through the screw electrodes by a stimulus isolator (SI-1850, World Precision Instruments, New Haven, CT, USA). Analog mMEP signals were amplified $(500000 \times)$, bandpass filtered $(100-2000 \mathrm{~Hz})$, and fed into a computer through a data acquisition unit (CED 1401 plus, Cambridge Electronic Design, Cambridge, UK). Ten mMEP traces with a sweep length of $50 \mathrm{~ms}$ were averaged before saving.

The area under the mMEP wave was measured using a software program (ImageJ 1.45, NIH, Bethesda, MD, USA) to indicate the number of axons involved in the impulse conduction through the corticospinal tracts. The onset latency of the mMEP wave was measured as the time difference between the stimulus-artifact point and the wave-initiation point. The post-transplantation area and latency values were expressed as percentages of the pre-SCI values.

\section{Quantification of myelinated axons in the ventrolateral white matter}

We used toluidine blue staining to examine the extent of improvement in the myelination of the spinal motor axons after SCI in OPC-like cell-transplanted $(n=5)$ and PBS vehicle-treated $(n=5)$ rats that had completed the 9-week behavioral test and in sham-operated rats $(n=3)$ that underwent the same surgical procedures but without SCI and cell transplantation or PBS injection. The animals were anesthetized with urethane $\left(1.5 \mathrm{~g} \mathrm{~kg}^{-1}\right.$, i.p.) and perfused with $0.1 \mathrm{~m}$ phosphate buffer $(\mathrm{PB})$ and $2 \%$ paraformaldehyde plus $2 \%$ glutaraldehyde in $0.1 \mathrm{M} \mathrm{PB}$. The spinal cord was dissected to collect three slices (each $1 \mathrm{~mm}$ in thickness) at the lesion epicenter and at sites $5 \mathrm{~mm}$ rostral and $5 \mathrm{~mm}$ caudal to the lesion epicenter, respectively. The spinal cord slices were incubated in the same fixatives overnight at $4{ }^{\circ} \mathrm{C}$ and then washed in $0.1 \mathrm{M} \mathrm{PB}$. For semi-thin sections, the cord slices were post fixed with $1 \% \mathrm{OsO}_{4}$ dissolved in $0.1 \mathrm{M} \mathrm{PB}$ for $2 \mathrm{~h}$, dehydrated in ascending gradual ethanol series (50-100\%), and infiltrated with propylene oxide. The cord slices were embedded 
using a Poly/Bed 812 kit (Polysciences, Warrington, PA, USA) and polymerized by ultraviolet irradiation at $60^{\circ} \mathrm{C}$ in an electronmicroscope oven (TD-700, DOSAKA EM, Kyoto, Japan) for $24 \mathrm{~h}$. Using an ultra-microtome (Leica Ultracut UCT, Wetzlar, Germany), the cord slices were cut coronally into $1-\mu \mathrm{m}$-thick semi-thin sections. Every 100th section was collected and stained with toluidine blue to visualize myelinated axons under light microscopy (Powershot A620, Canon, Tokyo, Japan).

To quantify the myelination of the spinal motor axons, the myelinated axons in the ventrolateral white matter of the spinal cord were sampled for examination. The crossed central lines of a gridded microscope eyepiece were initially adjusted over the semi-thin sections at $\times 40$ magnification by rotating the eyepiece so that one line ran vertically between the outermost center points of the dorsal and ventral columns, the other line ran horizontally across lateral columns on both sides of the spinal cord, and the line-line intersection was positioned on the central canal. The region of ventrolateral white matter was then located at $\times 100$ magnification by adjusting the microscope stage to move the intersection point of the grid lines in the radial direction from the central canal to the outermost limit of the spinal cord. When the center of the field of view reached the area near the outermost boundary of the ventrolateral white matter, the magnification was increased to $\times 400$, and an image was captured by a digital camera. The digital images were processed with Photoshop (Adobe, San Jose, CA, USA) and overlaid with a square frame $\left(50 \times 50 \mu \mathrm{m}^{2}\right)$. The myelinated axons in $2500 \mu \mathrm{m}^{2}$ areas, which were sampled from the ventrolateral white matter on both sides of the spinal cord in each of 10 semi-thin sections collected from three different cord levels of each rat, were counted and averaged for analysis. The axon counts, behavioral, and mMEP assessments were performed by investigators who were blind to the surgery and treatment that the animals had received.

\section{Immunohistochemistry}

To evaluate the characteristics of the transplanted cells in vivo, we performed immunohistochemical staining using three OPC-like a

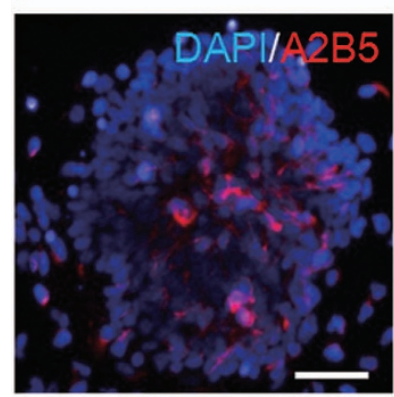

d

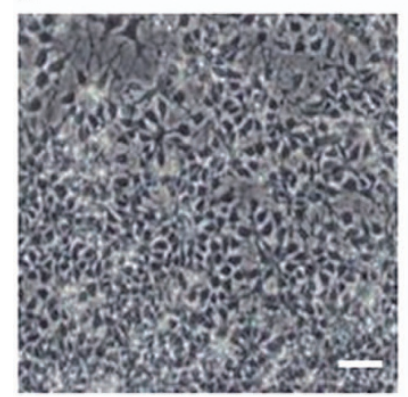

g

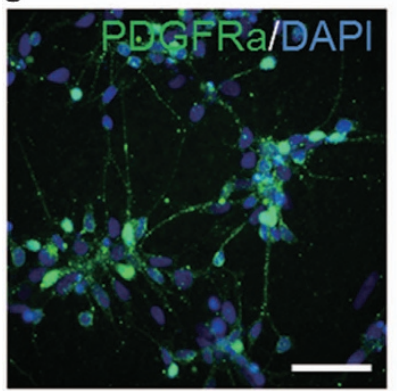

b

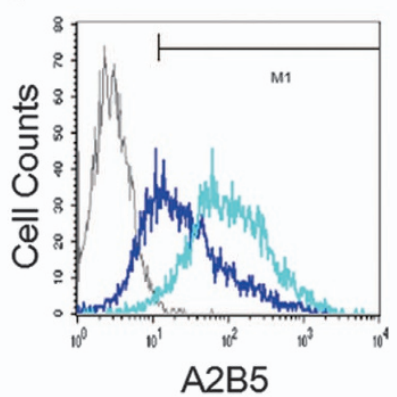

e

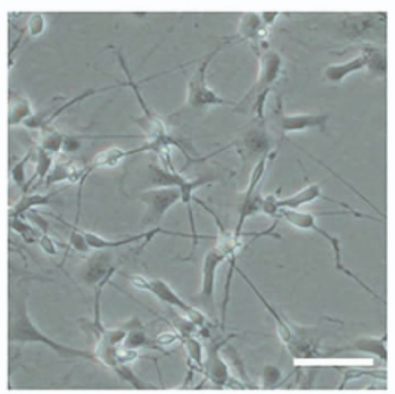

h

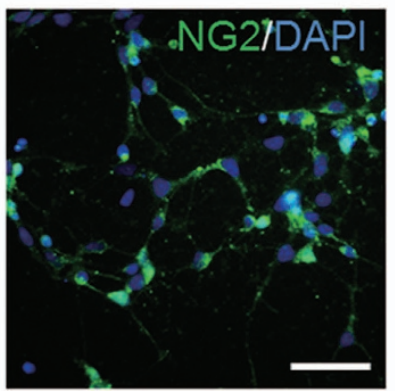

C

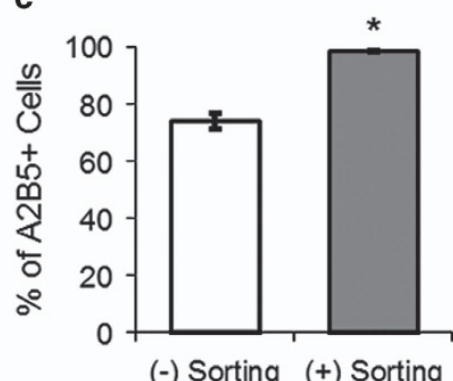

$(-)$ Sorting (+) Sorting

f

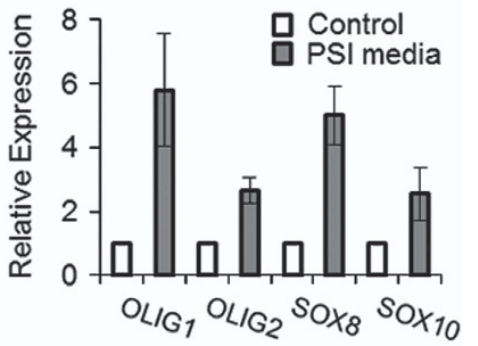

i

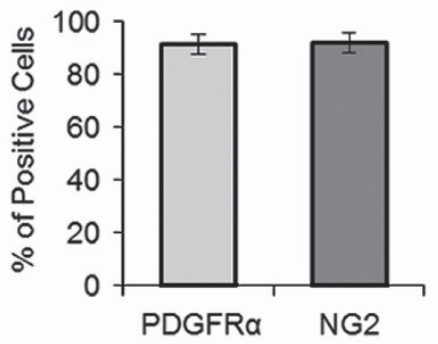

Figure 1 OPC-like cells differentiated from human pluripotent stem cells. (a) A2B5-immunoreactive cells in the neural rosette stage on day 10 of differentiation. (b, c) Flow cytometry analysis reveals enrichment of the A2B5-positive population (a dark blue peak before cell sorting vs a light blue peak after cell sorting). (d, e) Bright-field images of OPC-like cells cultured in PSI medium. (f) Culture in PSI media upregulated expression of genes involved in OD specification. (g-i) Immunocytochemical analysis shows a high yield of PDGFR $\alpha$-positive and NG2-positive cells in the OPC-like cell culture. Scale bars represent $25 \mu \mathrm{m}$. Error bars indicate s.e.m. ${ }^{*} P<0.05$, Student's t-test. 
cell-transplanted SCI rats that had completed the 9-week behavioral test. The animals were anesthetized with urethane $\left(1.5 \mathrm{~g} \mathrm{~kg}^{-1}\right.$, i.p.) and perfused with PBS and 4\% paraformaldehyde in PBS. The full length of the spinal cord from $6 \mathrm{~mm}$ rostral of the lesion epicenter to $6 \mathrm{~mm}$ caudal of the lesion epicenter was dissected and post fixed for 4-6 h with 4\% paraformaldehyde, immersed overnight in 30\% sucrose in $0.1 \mathrm{M}$ PBS, and embedded in an OCT compound (Tissue-Tek, Torrance, CA, USA). Some of the fixed cord segments were cut into $10 \mu \mathrm{m}$ sagittal sections, and others were cut into $10 \mu \mathrm{m}$ coronal sections using the cryostat. Every tenth cord section was collected, mounted onto gelatin-coated slides, and stored at $-70{ }^{\circ} \mathrm{C}$ before immunostaining was performed.

Immunohistochemistry was conducted with sagittal sections to identify oligodendrocytes that had differentiated from the transplanted OPC-like cells and with coronal sections to identify other graft-derived cells. The cord sections were rinsed with PBS three times, blocked overnight with $3 \%$ bovine serum albumin in PBS containing $0.3 \%$ Triton X-100, and incubated with primary antibodies for 1 day at $4{ }^{\circ} \mathrm{C}$ in the presence of a blocking solution. The primary antibodies used for the sagittal sections were mouse anti-human nuclei (HNA) monoclonal antibody (1:100, Millipore) and rabbit anti-myelin basic protein (MBP; 1:200, Millipore). The primary antibodies used for the coronal sections were HNA, rabbit anti-microtubule associated protein 2 (MAP2; 1:100, Millipore), rabbit anti-glial fibrillary acidic protein (GFAP; 1:500, Millipore), and rabbit anti-ki67 (1:150, Leica, Richmond, IL, USA). The cord sections were then washed, and species-specific secondary antibodies (anti-rat Alexa Fluor 488 or anti-mouse Alexa Fluor 594, 1:200; Molecular Probes) were applied for $1 \mathrm{~h}$ at room temperature. The slides were then cover-slipped with Vectashield (Vector Laboratories) containing the nuclear counter-stain DAPI and observed under a fluorescence microscope (BX50, Olympus) or confocal microscope (FV10-ASW, Olympus).

\section{Statistical analysis}

The results from the behavioral tests and mMEP recordings were analyzed with a two-way repeated measures analysis of variance (ANOVA). The data from the axon counts were analyzed with a two-way ANOVA. When the ANOVAs identified significant differences, pair-wise comparisons between mean values were performed using post hoc Tukey's tests. Statistical significance of FACS analysis (Figure 1c) was examined by Student's $t$-test with three independent experiments. Significance was set at $P<0.05$. The data are presented as the mean \pm s.e.m.

\section{RESULTS}

\section{Generation of OPC-like cells from hESCs}

We previously showed that NPs could be efficiently generated from hESCs via the simultaneous inhibition of BMP and Activin/Nodal signals. ${ }^{21} \mathrm{~EB}$ culture in the presence of two inhibitors (that is, $5 \mu \mathrm{M}$ dorsomorphin and $5 \mu \mathrm{M}$ SB431542) and subsequent adherent culture in neural-inducing medium generated robust clumps of neural cells, which we refer to as neural rosettes, from hESCs within a week (Supplementary Figure $1 \mathrm{~A}-\mathrm{C}$ ). We mechanically dissected the radially arranged, columnar-shaped cells in the neural rosettes under a dissection microscope and passed them onto a Matrigel-coated culture dish for expansion. Consistent with our previous finding, ${ }^{26}$ immunocyto-chemical analysis confirmed that the cells at that stage strongly expressed several neural markers, including
SOX1, PAX6, Nestin and Musashi-1 (Supplementary Figure 1D and E). RT-PCR analysis of the time-course of gene expression revealed that the expression of the neural markers was induced and sustained over the period of differentiation, whereas the expression of OCT4, a marker of pluripotency, was reduced as the differentiation proceeded (Supplementary Figure 1F). When we examined the expression of A2B5, a substantial proportion $(\sim 70 \%)$ of the cells were positive (Figure 1a and c), but the proportion of positive cells did not significantly increase even after further prolonged expansion in medium supplemented with EGF, which is used to expand NPs for OPC differentiation $^{27}$ (data not shown). Because A2B5-expressing cells are the first population to emerge in OD differentiation, we decided to enrich the A2B5-positive cells and expose them to the culture conditions favorable for OPCs, expecting that such an approach might curtail the period required for expansion and facilitate the commitment of the cells toward OPCs. To enrich the A2B5-positive population, we took advantage of cell sorting using magnetic beads conjugated with an A2B5 antibody, which is relatively benign to the cells and easily scalable. ${ }^{28}$ After expanding cells from the neural rosettes, we were able to use the cell sorting to enrich the A2B5-positive cells up to $95 \%$ of the total cell population and greatly reduce the variation among the cells (Figure $1 b$ and $c$ ). We obtained comparable results using another hiPSC line as well (Supplementary Figure 2).

To further differentiate the A2B5-positive cells into OPCs, we cultured them in medium supplemented with $10 \mathrm{ng} \mathrm{ml}^{-1}$ PDGF-AA, $100 \mathrm{ng} \mathrm{ml}^{-1} \mathrm{SHH}$ and $10 \mathrm{ng} \mathrm{ml}^{-1}$ IGF-1 (hereafter referred to as PSI medium), all well-known factors for the induction and maintenance of OPCs. ${ }^{29-31}$ After 7-10 days of additional culture in the PSI medium, most of the cells displayed an oval-shaped cell body with two or three long processes, the typical morphology of pre-OPCs ${ }^{32}$ (Figure 1d and e). RT-PCR analysis revealed that the cells cultured in the PSI medium upregulated their expression of several genes involved in OD survival and specification, ${ }^{33,34}$ including SOX8/10, members of the SOX (SRY-related HMG-box) family of transcription factors, and OLIG1/2, basic helix-loop-helix transcription factors, which are essential for OD development ${ }^{35}$ (Figure 1f). When we further examined the expression of OPC markers by immunocytochemistry, the great majority of the cells were labeled with anti-PDGFR $\alpha$ and NG2 antibodies $(91.2 \pm 3.8 \%$ and $91.7 \pm 3.7 \%$, respectively; Figure 1g-i). Because the cells exhibited immunoreactivity against multiple markers, including A2B5, PDGFR $\alpha$ and NG2, as well as enhanced expression of OPC markers as determined by RT-PCR, we referred to these cells as 'OPC-like' cells.

In addition to enriching the cells of interest, the cell sorting should also exclude unwanted cells, including undifferentiated remnants from the culture which might cause undesirable tissues to form after transplantation. ${ }^{36}$ As expected, multiple immunocytochemical examinations showed that cells expressing OCT4 and/or NANOG were absent from the culture after the A2B5-mediated cell sorting (Supplementary Figure 3). 
a

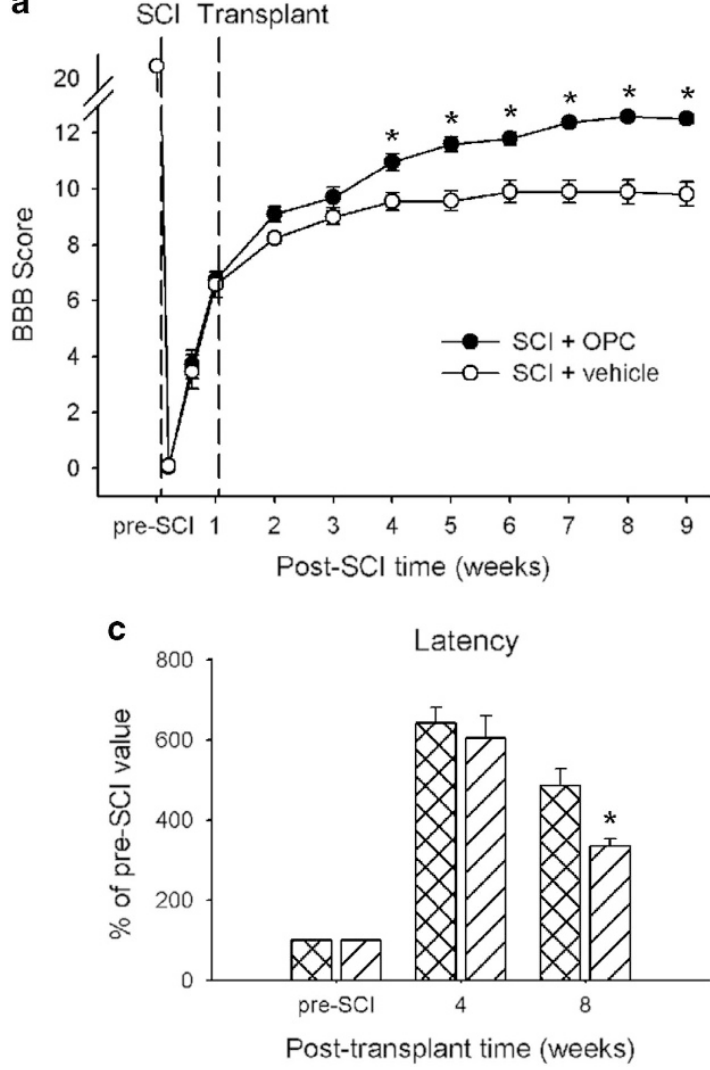

b
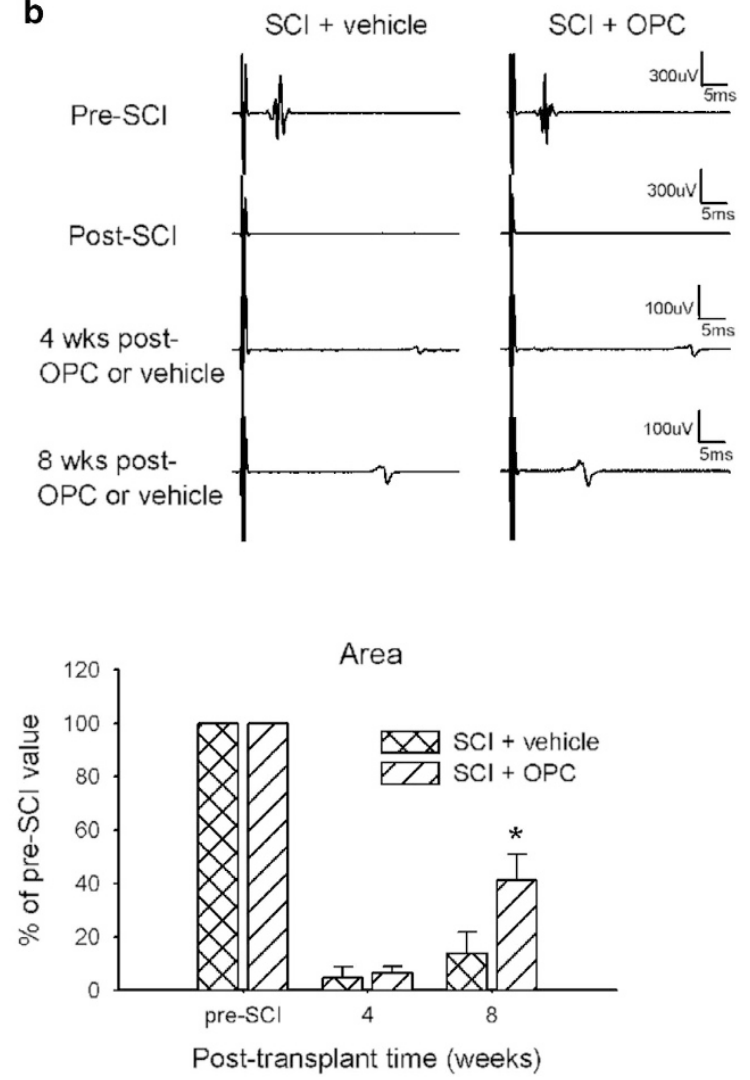

Figure 2 Recovery of hindlimb locomotor function and mMEPs in SCI rats after OPC-like cell transplantation. (a) The average BBB score of both hindlimbs for each rat was assessed in two groups: rats receiving cell transplants or PBS, respectively, 1 week after SCI. The functional test shows a significant improvement in the $\mathrm{SCl}$ rats treated with cell transplants compared with those treated with PBS, beginning at least 3 weeks after cell transplantation. (b) Representative waveforms of mMEPs in rats that underwent SCl followed by treatment with either cell transplantation or PBS immediately before and after SCl and at weeks 4 and 8 post transplantation. (c) The onset latency of mMEP and the area under the mMEP wave were evaluated with respect to the pre-SCl value. Eight weeks post transplantation, the cell-transplanted $\mathrm{SCl}$ rats displayed a significant decrease in the onset latency and a significant increase in the area under the mMEP wave compared with the PBS-treated controls. No significant difference in these two measures between the groups was observed 4 weeks post transplantation. Error bars indicate s.e.m. ${ }^{*} P<0.05$.

Together with the RT-PCR data showing the lack of OCT4 transcripts (Supplementary Figure $1 \mathrm{~F}$ ), the results showed that the populations obtained by the cell sorting had a more reliable phenotype and were thus more compatible with the purpose of transplantation and less likely to lead to teratoma formation.

\section{Improvement of hindlimb locomotor recovery in SCI rats after OPC-like cell transplantation}

To test the potential of OPC-like cells as a therapy to treat SCI, we transplanted the cells into the lesion site in SCI rats and assessed locomotor function using the $\mathrm{BBB}$ scale. The rats completely lost their hindlimb mobility $(\mathrm{BBB}$ score $=0$ ) bilaterally after SCI (Figure 2a). The SCI rats progressively recovered some locomotor activity, however, with some movement of the hip, knee and ankle joints $(\mathrm{BBB}$ score $=5-7)$; during the first week post SCI, after which they received transplantation of OPC-like cells $(n=11)$ or PBS vehicle $(n=9)$ into the lesion site. The SCI rats that received the PBS injection recovered further, up to a BBB score of $\sim 9$ through 3 weeks post PBS treatment, showing weight- supported stepping using the dorsum, but not the sole, of the foot. However, compared with those of the PBS-treated control rats, the BBB scores of the rats that received the OPC-like cell transplants significantly increased from 3 weeks post transplantation to the last day of behavioral testing $(P<0.05)$, indicating that the OPC-like cell transplantation significantly improved locomotor recovery in the SCI rats. The improved locomotor function included weight-supported stepping using the sole of the foot and locomotor activity with coordinated forelimb and hindlimb movement.

To assess the functional integrity of the descending axons from the motor cortex directly or indirectly through the brainstem to the spinal cord, we recorded mMEPs from the contralateral gastrocnemius muscle in SCI rats given OPC-like transplants $(n=16)$ or PBS injection $(n=9)$. The mMEPs, the conduction of which was blocked by the SCI, began to reappear 4 weeks after transplantation (Figure 2b); however, no significant differences in the area under the wave form or the onset latency between the two groups were observed at 4 weeks post transplantation. Eight weeks after transplantation, 
however, the mMEPs in the rats that underwent OPC-like transplantation showed larger amplitudes and faster conduction velocities than those in the rats that received the PBS injections. The onset latency and area under the MMEP wave were quantified as indicators of recovery of the functional integrity of the descending axons from the somatomotor cortex (Figure 2c). Eight weeks after transplantation, the rats that received the OPC-like transplants demonstrated a significant decrease in the mMEP onset latency and a significant increase in the area under the MMEP wave form compared with the rats that received the PBS injections $(486.3 \pm 41.9 \%$ vs $335.8 \pm 18.1 \%, P<0.05 ; 13.7 \pm 1.8 \%$ vs $41.7 \pm 9.6 \%, P<0.05$; respectively).

Increased numbers of myelinated axons in the ventrolateral white matter after OPC-like cell transplantation

To assess the anatomical substrate for the functional improvement of the descending axons from the somatomotor cortex after OPC-like cell transplantation, we investigated whether OPC-like transplantation increased the number of myelinated axons in the ventrolateral white matter of the spinal cord. After toluidine blue staining to visualize the myelinated axons, we counted the numbers of myelinated axons in squares $\left(50 \times 50 \mu \mathrm{m}^{2}\right)$ placed on the ventolateral white matter in coronal sections collected at three different levels of the spinal cord: at the lesion epicenter, $5 \mathrm{~mm}$ rostral to the lesion epicenter, and $5 \mathrm{~mm}$ caudal to the lesion epicenter (Figure 3a). As shown in Figure 3b, myelin loss was apparent in the rats that received the PBS injections (middle lane). Conversely, the rats that received the OPC-like transplants had improved tissue integrity and increased numbers of myelinated axons around the injury site compared with the PBS-treated rats (Figure 3b, right). The SCI rats given OPC-like transplants often displayed thinner myelin sheaths compared with the sham-operated animals (unaffected myelin), which were presumably evidence of remyelinated axons ${ }^{37}$ or spared axons protected from massive demyelination $^{38}$ (Figure 3b, III). Cell-count analysis of the myelinated axons (Figure 3c) revealed that the rats that received the OPC-like transplants had significantly more myelinated axons at all cord levels compared with those that received the PBS injections $(95.7 \pm 5.8$ vs $73.8 \pm 2.8$ at $5 \mathrm{~mm}$ rostral to the lesion epicenter, $80.4 \pm 10.4$ vs $55.2 \pm 4.2$ at the lesion epicenter, and $91.5 \pm 3.8$ vs $73.9 \pm 2.9$ at $5 \mathrm{~mm}$ caudal to the lesion epicenter; $P<0.05$ for each comparison); although they had fewer myelinated axons than the sham-operated rats $(116.5 \pm 7.5,114.2 \pm 2.3$ and $105.7 \pm 2.3$ at the three cord levels, respectively; $P<0.05$ for each comparison), which explains the partial recovery of locomotor function by cell transplantation. Taken together, our data strongly suggest that the transplantation of OPC-like cells increased the number of myelinated axons, supporting the potential of OPC-like cells to serve as a source for treating SCI-induced motor deficits.

\section{Fate of the transplants at 8 weeks after transplantation}

Next, we examined the fate of the OPC-like cell grafts in the injured spinal cords. Eight weeks post transplantation, the grafts showed strong survival and extended migration within the injured spinal cords, as shown by immunostaining with HNA (Figure 4a). Many HNA-positive cells occupied the lesion cavity induced by the SCI and migrated both rostrally and caudally to distances of at least $5 \mathrm{~mm}$ from the transplant site, with the vast majority of HNA-positive cells remaining near the transplanted area. As evidenced by triple labeling with DAPI, anti-HNA and anti-MBP antibodies (Figure $4 \mathrm{~b}$ ), a considerable number of HNA-positive cells was located adjacent to the areas of MBP immunoreactivity throughout the transplanted cells, suggesting the presence of myelinating cells derived from the transplanted OPC-like cells. HNA/GFAP double-positive cells and HNA/MAP2 double-positive cells were frequently observed throughout the injection area (Figure $4 \mathrm{c}$ and $\mathrm{d},<20 \%$ of surviving transplanted cells in both cases), which suggest that the OPC-like cells retained tripotency, likely because they were not fully committed toward the OD lineage. In addition, Ki67-positive cells were occasionally detected among the transplanted cells (Figure 4e), indicating that a few transplanted cells did not fully differentiate into the mature cells even 8 weeks after transplantation. We did not, however, find evidence of formation of non-neural tissues, neoplastic cell masses or teratomas. Collectively, our evidence shows that although the OPC-like cells were not fully committed to exclusively generate ODs, they had the potential to generate cells that were able either to create myelin sheaths on axons or to protect axons from massive demyelination after transplantation into the spinal cords of rats with contusion injuries.

\section{DISCUSSION}

We showed that the enrichment of A2B5-positive cells from hPSC-derived neural rosette cells, and exposure of the enriched cells to signaling cues implicated in oligodendrogenesis, robustly generated OPC-like cells expressing PDGFR $\alpha$ and NG2 within a short time period ( $\sim 4$ weeks). After transplantation into traumatically injured rat spinal cords, the OPC-like cells were well integrated into the injured tissue and were able to differentiate MBP-positive cells. Our in vivo evidence demonstrated that (1) the number of myelinated axons in the injured spinal cords that received OPC-like cells was significantly increased compared with that in control spinal cords; (2) the neural conduction evoked by electric stimulation through the injury site was enhanced by the OPC-like transplants; and (3) distinctive MBP immunoreactivity was frequently observed contiguous with HNA immunoreactivity in the cell-injection site. Collectively, our results demonstrate a fast and efficient differentiation system for hPSCs that can provide a cell source with the potential to improve motor dysfunction caused by SCI.

As highlighted by several studies, ${ }^{39,40}$ one of the challenges of OD differentiation from hPSCs is that the procedure is time-consuming and requires multiple steps. One can assume that when long periods of time are required to obtain cells of interest, the final cell populations will have a large amount of variation in yield and an increased risk of contamination (for example, by microorganisms or unwanted cell lineages). 
a

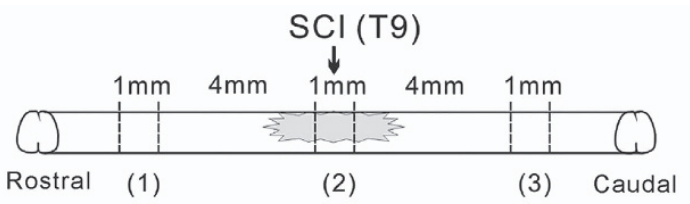

b
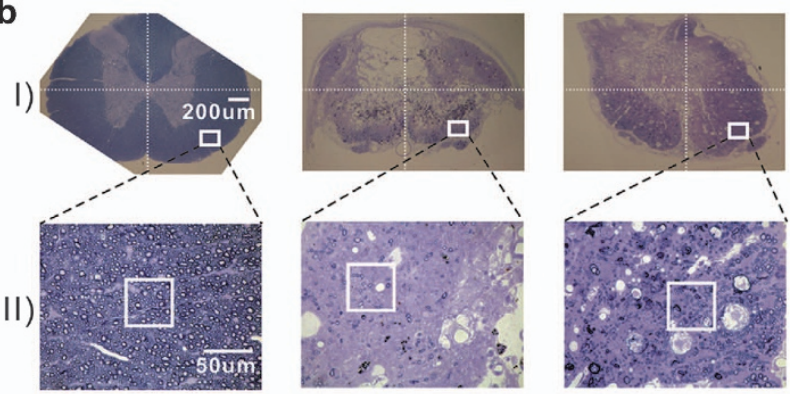

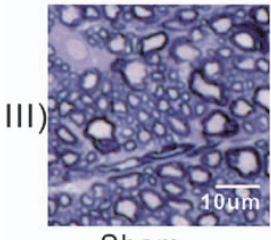

Sham

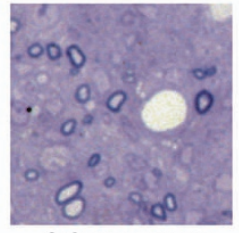

$\mathrm{SCl}+$ vehicle

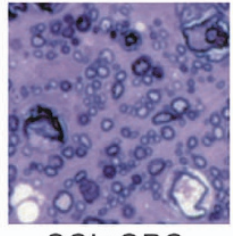

$\mathrm{SCI}+\mathrm{OPC}$ c

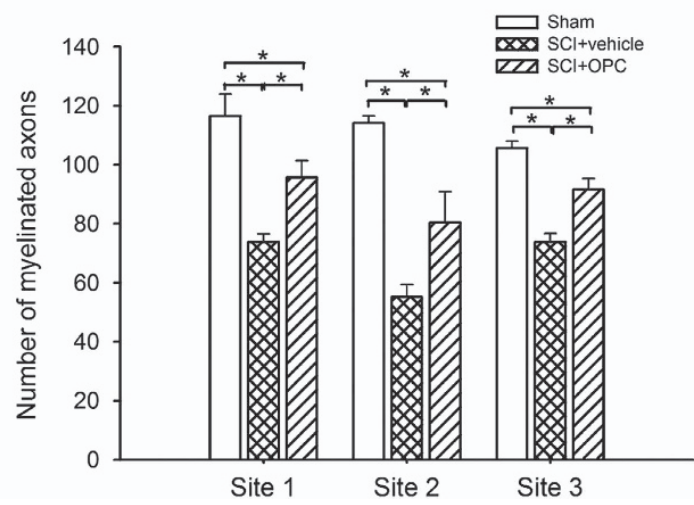

Figure 3 Histochemical detection of myelination 8 weeks after $\mathrm{OPC}$-like cell transplantation in $\mathrm{SCl}$ rats. (a) A diagram showing the locations at which the 1-mm-cord slice was dissected from the spinal cord to count the myelinated axons: the lesion epicenter, $5 \mathrm{~mm}$ rostral to the lesion epicenter and $5 \mathrm{~mm}$ caudal to the lesion epicenter. (b) Photomicrographs of coronal sections from individual $1 \mathrm{~mm}$ cord slices, stained with toluidine blue, in sham-operated rats and $\mathrm{SCl}$ rats treated with OPC-like cell transplants or PBS vehicle. Areas in the ventrolateral white matter were initially located at $\times 40$ magnification (insets in $b(i)$ ); images were then magnified up to $\times 400$ and captured by a digital camera (b(ii)). A square frame $\left(50 \times 50 \mu \mathrm{m}^{2}\right)$ randomly overlaid on the digital images was magnified for cell counting (b(iii)). (c) Histograms displaying the mean number of myelinated axons in the squares sampled from the ventrolateral white matter on both sides of the spinal cord over each of 10 semi-thin sections obtained at each spinal cord location in a given rat. The mean numbers of myelinated axons were significantly increased at all cord levels in the OPC-like cell-transplanted $\mathrm{SCl}$ rats compared with the vehicle-treated $\mathrm{SCl}$ rats, although these increased numbers were smaller than the increased numbers of myelinated axons observed in the sham-operated rats. Error bars indicate s.e.m. ${ }^{*} P<0.05$.
Accordingly, such time-consuming approaches might also be expected to come with higher costs and labor requirements for quality control, which could be a significant factor in delaying their transition to clinical applications. In an attempt to resolve those limitations, the goal of the present study was the acquisition of transplantable OPC-like populations in a way that is significantly faster than previous methods. Our strategy was to enrich NPC populations with cells that had a fate restricted to the OD lineage by sorting for A2B5-positive cells. The monoclonal antibody A2B5 was originally characterized as detecting a specific glycoprotein expressed on neurons, ${ }^{41}$ which was subsequently shown to be expressed on glial-lineage cells (that is, type- 2 astrocytes and OPCs ${ }^{42}$ ). Taking advantage of that specificity, previous studies utilized A2B5 immunoreactivity to identify and/or enrich a cell source appropriate for transplantation to repair demyelinated lesions from either rodent fetal neural tissue ${ }^{43}$ or mESC-derived NPs. ${ }^{44,45}$ Subpopulations of A2B5-positive cells (negative for polysialic acid-neural cell adhesion molecule) isolated from fetal and adult human brain tissues have been transplanted and have successfully generated myelin sheaths on axons in animal brains with congenital defects in myelination. ${ }^{46}$ Those results provided a reasonable clue for using A2B5 to enrich hPSC populations with cells that are committed toward OD differentiation. It has been generally believed, however, that OPCs could not be identified by the expression of a single marker and that multiple immunoreactivities of several markers are instead needed to identify cells fated to become OPCs. ${ }^{39}$ Furthermore, in contrast to the A2B5-positive cells obtained from fetal or adult brain tissues with defined ages and localizations, A2B5-positive cells obtained from hPSCs are not well characterized in terms of developmental stage, cellular phenotype and fate. In fact, the A2B5-positive cells that first emerged at the neural rosette stage lacked PDGFR $\alpha$ and NG2 expression (data not shown) and even retained the potential to generate neurons and astrocytes when placed in spontaneous differentiation conditions in vitro (Supplementary Figure 4), suggesting that they were unlikely to be fully committed to forming OPCs. Our endeavor to further commit their fate to the formation of OPCs led to the discovery that the exposure of A2B5-positve cells to signaling cues, including PDGF-AA, SHH and IGF-1, robustly increases the number of cells positive for PDGFR $\alpha$ and NG2 in the culture (Figure 1). The upregulated expression of genes implicated in OD lineage specification (that is, SOX8/10 and OLIG1/2) induced by the treatment strongly supports the commitment of A2B5-positive cells to the OPC fate (Figure 1).

To date, evidence has been accumulating that PDGFR $\alpha$ positive and/or NG2-positive cells might represent populations that contribute to the generation of ODs in the CNS. ${ }^{39}$ A previous report on the specific gene-expression profile of A2B5-positive populations obtained from human white matter-progenitor cells showed enriched expression of PDGFR $\alpha$ and NG2, suggesting that the co-expression of those three markers can define OPCs. ${ }^{47}$ More recent results by the same group suggested that cells positive for CD130a (a PDGFR $\alpha$ ecto-domain) isolated from human fetal brain 
a

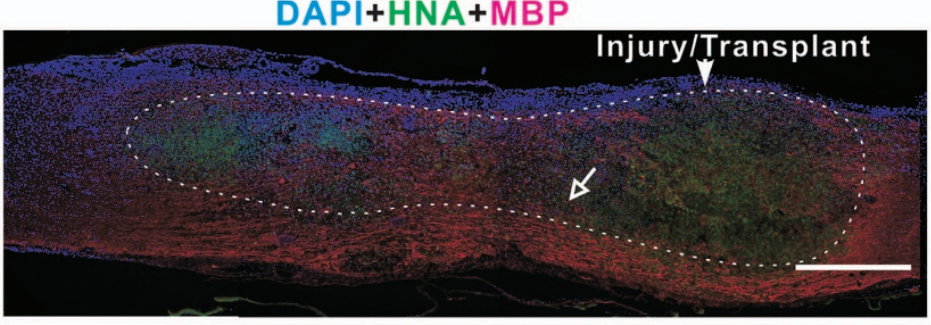

b
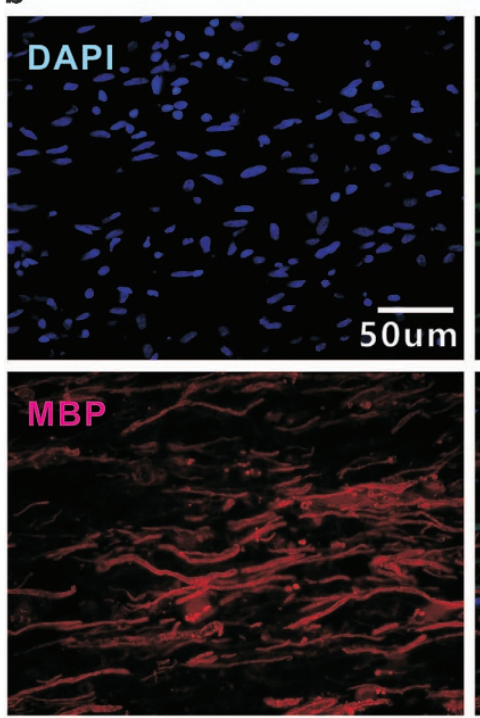

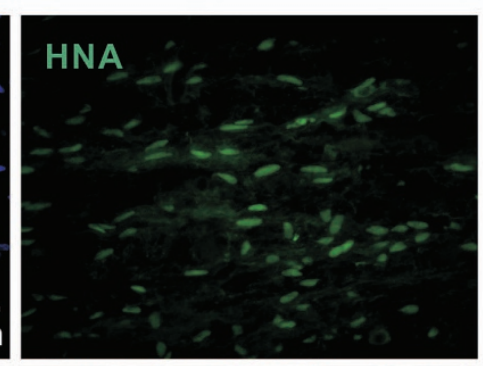

DAPI HNA, MBP

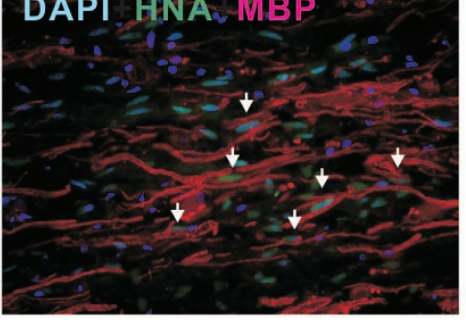

C

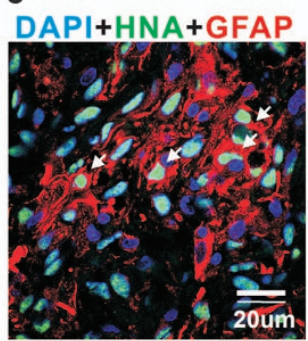

d

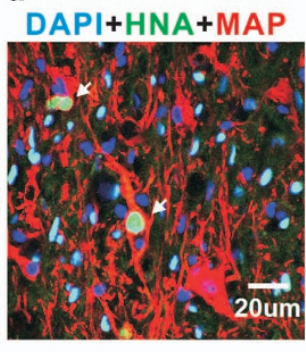

e

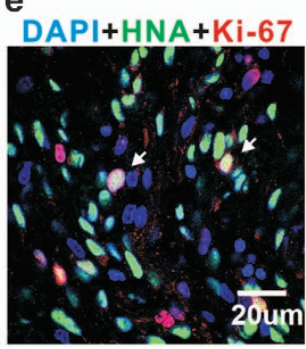

Figure 4 Cells derived from the OPC-like transplants in the injured spinal cord 8 weeks post transplantation. (a) A sagittal section image of the spinal cord illustrating the lesion/transplant site, adjacent area and injury-induced lesion cavity (area within the dotted line) filled with transplants. HNA-positive cells (green) survived and migrated both rostrally and caudally within the injury-induced cavity to distances of at least $5 \mathrm{~mm}$ from the transplanted site. Although the majority of HNA-positive cells was located within $1.5-3 \mathrm{~mm}$ rostral and caudal to the transplanted site, a larger proportion of cells migrated rostrally. (b) High-magnification images of the small area indicated by the open-headed arrow in a. The survival of oligodendrocytes derived from the transplants was confirmed by triple labeling with DAPI, anti-HNA and anti-MBP antibodies (arrows in photo at the bottom right). (c-e) Coronal section image of the spinal cord, showing other types of surviving cells derived from the transplants (arrows); (c) GFAP-positive cells (red), (d) MAP-positive cells (red) and (e) Ki67-positive cells (red) that are proliferative.

tissue were mutually responsible for the myelinogenic potential displayed by subpopulations of A2B5-positive cells. ${ }^{48}$ Another study showed that the transplantation of A2B5/NG2 double-positive cells isolated from human fetal tissue significantly improved the recovery of locomotor and sensory function in an SCI rat model. ${ }^{49}$ These results collectively support the idea that NPs with $\mathrm{A} 2 \mathrm{~B} 5 / \mathrm{PDGFR} \alpha / \mathrm{NG} 2$ tripleimmunoreactivity might present the genuine features of OPCs that first emerge in human CNS development and thus serve as a suitable source of cells to replace ODs lost due to SCI.

The OPC-like phenotypes within the A2B5-positive population were acquired in a relatively short period of time in our differentiation condition. This is probably because the increased purity of the cell population makes the cells more amenable to signaling cues that commit them to an OPC-like fate. PDGF (particularly the PDGF-AA isoform) has been used as a 'common factor' in previous studies for OD differentiation from hPSCs $^{39}$ due to its crucial role in the specification of OPCs in mammalian development. ${ }^{50,51}$ In addition, mouse genetic studies have demonstrated that Shh is an essential component of Olig1/2 expression, thereby inducing the development of ODs. ${ }^{30,52}$ Those results were supported by recent evidence that $\mathrm{SHH}$ treatment is required for OPC specification through the induction of OLIG2, NKX2.2 and SOX10 in hESC-derived NPCs patterned to a caudal fate. ${ }^{53}$ IGF-1 was also shown to retain an instructive effect on neural progenitors for OD differentiation by modulating BMP signaling, ${ }^{31}$ which prompted multiple studies to employ IGF-1 treatment in the differentiation of OPCs/ODs from hPSCs. ${ }^{53,54}$ The combination of these three signaling cues might be the main factor contributing to the fast specification of OPC lineages from pure populations of A2B5-positive NPCs. Finally, the utility of fibronectin as an extracellular matrix component might facilitate the differentiation of NPCs to OPC lineages, as it was reported that fibronectin showed a greater effect on the growth and differentiation of OPCs than any of the other extracellular matrix components tested. ${ }^{55}$ Hence, we conclude that the combination of OPC-inducing 
cues and appropriate extracellular matrix synergistically contribute to the early differentiation of pure populations of A2B5-positive cells to OPCs within a short period of time.

In addition to providing rapid differentiation to the desired cell type, our method provides a cell source that does not appear to lead to deleterious outcomes after transplantation, such as tumor formation. The transplantation of hPSC-derived neural cells retains the possibility of contamination by undifferentiated or unwanted cells (for example, cells of a non-neural lineage), especially in cases where cells that might not be fully committed to a specific lineage are used for transplantation. ${ }^{56}$ In this regard, we undertook efforts to reduce the heterogeneity of the cells by (1) developing an efficient differentiation strategy to minimize unwanted cell populations and (2) sorting the cells based on markers specific to the cells of interest. Our previous results showed an absence of meso-endodermal derivatives and undifferentiated remnants after neural induction by the strong and simultaneous inhibition of BMP and Activin/Nodal signals. ${ }^{36}$ Furthermore, cell sorting based on a neural-specific marker excludes the possibility of contamination by unwanted cells. The absence of any abnormal tissues after cell transplantation strongly suggests that the combination of those two paradigms makes our method amenable to cell replacement therapy for SCI.

Although the data presented in our study support the regenerative potential of OPC-like cells, one must be cautious in interpreting the improvement of locomotor function after cell transplantation to mean that the outcome is indeed directly driven by remyelination of spared axons by OPC-like transplants. In general, benefits of stem/precursor-cell transplantation include neuro-protective effects. Therefore, we cannot exclude the possibility that an increased number of myelinated axons in the spinal cords that received the cell transplantation (Figure 3) resulted from paracrine effects of the graft (that is, through secreting growth factors and neurotrophic factors) to either protect the cells in the injury site from massive cell death ${ }^{57}$ or to direct endogenous stem cells to differentiate. ${ }^{58}$ This idea is widely supported by numerous studies. For example, bFGF, which is known to be secreted from hPSC-derived neural progenies injected in animal brains, ${ }^{59}$ has been shown to have neuroprotective, angiogenic and cavitation-reducing effects (reviewed in ref. 60). In addition, recent evidence has shown that dormant ependymal cells start dividing, migrating and giving rise to oligodendrocytes after spinal cord injury ${ }^{61}$ and that the co-administration of EGF and bFGF promoted the proliferation of ependymal cells in adult rat spinal cord. ${ }^{62}$ Thus, a pleiotrophic factor such as bFGF might be one of several paracrine factor candidates that induce further beneficial effects on locomotor function in addition to myelination following OPC-like cell transplantation. There is also the possibility that the increased number of myelinated axons and MBP immunoreactivity around HNA-positive nuclei may originate from Schwann cells, which are myelinating cells in the peripheral nervous system, that are differentiated from OPC-like cells (as in recent studies showing Schwann cell differentiation from CNS glial stem cells ${ }^{63}$ ). Thus, in order to define the exact role of OPC-like cell transplantation in injured spinal cords, further assessment regarding grafted cell-fate determination and the origin of myelinating cells may be required.

Nevertheless, our results promptly contribute to overcoming current limitations, including the lengthy procedure time required to obtain transplantable OPCs. Although more detailed developmental mechanisms underlying our in vitro differentiation system and the role of OPC-like cells in improvement of locomotor function in SCI require further study, we believe that our current differentiation system represents a significant advancement toward obtaining a cell source from hPSCs for a pre-clinical study of replacement therapy for SCI.

\section{CONFLICT OF INTEREST}

The authors declare no conflict of interest.

\section{ACKNOWLEDGEMENTS}

This research was supported by the Bio \& Medical Technology Development Program of the National Research Foundation funded by the Korean government; MSIP (2015M3A9B4071076). D-WK was supported by grants from the National Research Foundation of Korea (the Bio and Medical Technology Development Program, 2012M3A9B4028631 and 2012M3A9C7050126) and from the Ministry of Health and Welfare (HI15C0916).

Author contributions: D-SK: conception and design, collection and/or assembly of data, data analysis and interpretation, manuscript writing. SJJ: collection of data, data analysis and interpretation. JSL, BYL, HAK and J-EY: collection of data. D-WK: conception and design, financial support, data analysis and interpretation, manuscript writing, and final approval of manuscript. JWL: conception and design, data analysis and interpretation, manuscript writing, and final approval of manuscript.

1 Noble M, Mayer-Pröschel M, Davies JE, Davies SJ, Pröschel C. Cell therapies for the central nervous system: how do we identify the best candidates? Curr Opin Neurol 2011; 24: 570-576.

2 Fawcett JW, Asher RA. The glial scar and central nervous system repair. Brain Res Bull 1999; 49: 377-391.

3 Parr AM, Tator $\mathrm{CH}$, Keating A. Bone marrow-derived mesenchymal stromal cells for the repair of central nervous system injury. Bone Marrow Transplant 2007; 40: 609-619.

4 Tetzlaff W, Okon EB, Karimi-Abdolrezaee S, Hill CE, Sparling JS, Plemel JR et al. A systematic review of cellular transplantation therapies for spinal cord injury. J Neurotrauma 2011; 28: 1611-1682.

5 Moreno-Manzano V, Rodríguez-Jiménez FJ, García-Roselló M, Laínez S, Erceg S, Calvo MT et al. Activated spinal cord ependymal stem cells rescue neurological function. Stem Cells 2009; 27: 733-743.

6 McDonald JW, Liu XZ, Qu Y, Liu S, Mickey SK, Turetsky D et al. Transplanted embryonic stem cells survive, differentiate and promote recovery in injured rat spinal cord. Nat Med 1999; 5: 1410-1412.

7 Keirstead HS, Nistor G, Bernal G, Totoiu M, Cloutier F, Sharp K et al. Human embryonic stem cell-derived oligodendrocyte progenitor cell transplants remyelinate and restore locomotion after spinal cord injury. J Neurosci 2005; 25: 4694-4705.

8 Mothe AJ, Tator $\mathrm{CH}$. Advances in stem cell therapy for spinal cord injury. J Clin Invest 2012; 122: 3824-3834.

9 Casha S, Yu WR, Fehlings MG. Oligodendroglial apoptosis occurs along degenerating axons and is associated with FAS and p75 expression following spinal cord injury in rats. Neuroscience 2001; 103: 203-218. 
10 Sharp J, Frame J, Siegenthaler M, Nistor G, Keirstead HS. Human embryonic stem cell-derived oligodendrocyte progenitor cell transplants improve recovery after cervical spinal cord injury. Stem Cells 2010; 28: 152-163.

11 Kawabata S, Takano M, Numasawa-Kuroiwa Y, Itakura G, Kobayashi Y, Nishiyam $Y$ et al. Grafted human iPS cell-derived oligodendrocyte precursor cells contribute to robust remyelination of demyelinated axons after spinal cord injury. Stem Cell Reports 2016; 6: 1-8.

12 All AH, Bazley FA, Gupta S, Pashai N, Hu C, Pourmorteza A et al. Human embryonic stem cell-derived oligodendrocyte progenitors aid in functional recovery of sensory pathways following contusive spinal cord injury. PLoS ONE 2012; 7: e47645.

13 Kobayashi Y, Okada Y, Itakura G, Iwai H, Nishimura S, Yasuda A et al. Pre-evaluated safe human iPSC-derived neural stem cells promote functional recovery after spinal cord injury in common marmoset without tumorigenicity. PLOS ONE 2012; 7: e52787.

14 Erceg S, Ronaghi M, Oria M, Roselló MG, Aragó MA, Lopez MG et al. Transplanted oligodendrocytes and motoneuron progenitors generated from human embryonic stem cells promote locomotor recovery after spinal cord transection. Stem Cel/s 2010; 28: 1541-1549.

15 Bretzner F, Gilbert F, Baylis F, Brownstone RM. Target populations for first-in-human embryonic stem cell research in spinal cord injury. Cell Stem Cell 2011; 8: 468-475.

16 Goldman SA, Kuypers NJ. How to make an oligodendrocyte. Development 2015; 142: 3983-3995.

17 Nakamura M, Okano H. Cell transplantation therapies for spinal cord injury focusing on induced pluripotent stem cells. Cell Res 2013; 23: 70-80.

18 Lukovic D, Stojkovic M, Moreno-Manzano V, Jendelova P, Sykova E, Bhattacharya SS et al. Concise review: reactive astrocytes and stem cells in spinal cord injury: good guys or bad guys? Stem Cells 2015; 33: 1036-1041.

19 Dubois C, Manuguerra JC, Hauttecoeur B, Maze J. Monoclonal antibody A2B5, which detects cell surface antigens, binds to ganglioside GT3 (II3 (NeuAc)3LacCer) and to its 9-O-acetylated derivative. J Biol Chem 1990; 265: 2797-2803.

20 Park IH, Zhao R, West JA, Yabuuchi A, Huo H, Ince TA et al. Reprogramming of human somatic cells to pluripotency with defined factors. Nature 2008; 451: 141-146.

21 Kim DS, Lee JS, Leem JW, Huh YJ, Kim JY, Kim HS et al. Robust enhancement of neural differentiation from human ES and iPS cells regardless of their innate difference in differentiation propensity. Stem Cell Rev 2010; 6: 270-281.

22 Jang J, Yoo JE, Lee JA, Lee DR, Kim JY, Huh YJ et al. Disease-specific induced pluripotent stem cells: a platform for human disease modeling and drug discovery. Exp Mol Med 2012; 44: 202-213.

23 Basso DM, Beattie MS, Bresnahan JC. Graded histological and locomotor outcomes after spinal cord contusion using the NYU weight-drop device versus transection. Exp Neurol 1996; 139: 244-256.

24 Gruner JA, Wade CK, Menna G, Stokes BT. Myoelectric evoked potentials versus locomotor recovery in chronic spinal cord injured rats. J Neurotrauma 1993; 10: 327-347.

25 Nashmi R, Imamura H, Tator CH, Fehlings MG. Serial recording of somatosensory and myoelectric motor evoked potentials: role in assessing functional recovery after graded spinal cord injury in the rat. J Neurotrauma 1997; 14: 151-159.

26 Kim DS, Lee DR, Kim HS, Yoo JE, Jung SJ, Lim BY et al. Highly pure and expandable PSA-NCAM-positive neural precursors from human ESC and iPSC-derived neural rosettes. PLOS ONE 2012; 7: e39715.

$27 \mathrm{Hu}$ BY, Du ZW, Zhang SC. Differentiation of human oligodendrocytes from pluripotent stem cells. Nat Protoc 2009; 4: 1614-1622.

28 Cizkova D, Cizek M, Nagyova M, Slovinska L, Novotna I, Jergova S et al. Enrichment of rat oligodendrocyte progenitor cells by magnetic cell sorting. J Neurosci Methods 2009; 184: 88-94.

$29 \mathrm{Hu}$ JG, Fu SL, Wang YX, Li Y, Jiang XY, Wang XF et al. Platelet-derived growth factor-AA mediates oligodendrocyte lineage differentiation through activation of extracellular signal-regulated kinase signaling pathway. Neuroscience 2008; 151: 138-147.

30 Lu QR, Yuk D, Alberta JA, Zhu Z, Pawlitzky I, Chan J et al. Sonic hedgehog-regulated oligodendrocyte lineage genes encoding $\mathrm{bHLH}$ proteins in the mammalian central nervous system. Neuron 2000; 25: 317-329.

31 Hsieh J, Aimone JB, Kaspar BK, Kuwabara T, Nakashima K, Gage FH. IGF-I instructs multipotent adult neural progenitor cells to become oligodendrocytes. J Cell Biol 2004; 164: 111-122.
32 Chen Y, Balasubramaniyan V, Peng J, Hurlock EC, Tallquist M, Li J et al. Isolation and culture of rat and mouse oligodendrocyte precursor cells. Nat Protoc 2007; 2: 1044-1051.

33 Stolt CC, Schmitt S, Lommes P, Sock E, Wegner M. Impact of transcription factor Sox8 on oligodendrocyte specification in the mouse embryonic spinal cord. Dev Biol 2005; 281: 309-317.

34 Pozniak CD, Langseth AJ, Dijkgraaf GJ, Choe Y, Werb Z, Pleasure SJ. Sox10 directs neural stem cells toward the oligodendrocyte lineage by decreasing suppressor of fused expression. Proc Natl Acad Sci USA 2010; 107: 21795-21800.

$35 \mathrm{Lu}$ QR, Sun T, Zhu Z, Ma N, Garcia M, Stiles CD et al. Common developmental requirement for Olig function indicates a motor neuron/ oligodendrocyte connection. Cell 2002; 109: 75-86.

36 Lee DR, Yoo JE, Lee JS, Park S, Lee J, Park CY et al. PSA-NCAM-negative neural crest cells emerging during neural induction of pluripotent stem cells cause mesodermal tumors and unwanted grafts. Stem Cell Reports 2015; 4: 821-834.

37 Griffiths IR, McCulloch MC. Nerve fibres in spinal cord impact injuries. Part 1. Changes in the myelin sheath during the initial 5 weeks. J Neurol Sci 1983; 58: 335-349.

38 Powers BE, Sellers DL, Lovelett EA, Cheung W, Aalami SP, Zapertov N et al. Remyelination reporter reveals prolonged refinement of spontaneously regenerated myelin. Proc Natl Acad Sci USA 2013; 110: 4075-4080.

39 Alsanie WF, Niclis JC, Petratos S. Human embryonic stem cell-derived oligodendrocytes: protocols and perspectives. Stem Cells Dev 2013; 22: 2459-2476.

40 Czepiel M, Boddeke E, Copray S. Human oligodendrocytes in remyelination research. Glia 2015; 63: 513-530.

41 Eisenbarth GS, Walsh FS, Nirenberg M. Monoclonal antibody to a plasma membrane antigen of neurons. Proc Natl Acad Sci USA 1979; 76: 4913-4917.

42 Williams BP, Abney ER, Raff MC. Macroglial cell development in embryonic rat brain: studies using monoclonal antibodies, fluorescence activated cell sorting, and cell culture. Dev Biol 1985; 112: 126-134.

43 Groves AK, Barnett SC, Franklin RJ, Crang AJ, Mayer M, Blakemore WF et al. Repair of demyelinated lesions by transplantation of purified $0-2 \mathrm{~A}$ progenitor cells. Nature 1993; 362: 453-455.

44 Brüstle O, Jones KN, Learish RD, Karram K, Choudhary K, Wiestler OD et al. Embryonic stem cell-derived glial precursors: a source of myelinating transplants. Science 1999; 285: 754-756.

45 Ogawa S, Tokumoto Y, Miyake J, Nagamune T. Immunopanning selection of A2B5-positive cells increased the differentiation efficiency of induced pluripotent stem cells into oligodendrocytes. Neurosci Lett 2011; 489: 79-83.

46 Windrem MS, Nunes MC, Rashbaum WK, Schwartz TH, Goodman RA, McKhann G 2nd et al. Fetal and adult human oligodendrocyte progenitor cell isolates myelinate the congenitally dysmyelinated brain. Nat Med 2004; 10: 93-97.

47 Sim FJ, Lang JK, Waldau B, Roy NS, Schwartz TE, Pilcher WH et al. Complementary patterns of gene expression by human oligodendrocyte progenitors and their environment predict determinants of progenitor maintenance and differentiation. Ann Neurol 2006; 59: 763-779.

48 Sim FJ, McClain CR, Schanz SJ, Protack TL, Windrem MS, Goldman SA. CD140a identifies a population of highly myelinogenic, migrationcompetent and efficiently engrafting human oligodendrocyte progenitor cells. Nat Biotechnol 2011; 29: 934-941.

49 Alexanian AR, Svendsen CN, Crowe MJ, Kurpad SN. Transplantation of human glial-restricted neural precursors into injured spinal cord promotes functional and sensory recovery without causing allodynia. Cytotherapy 2011; 13: 61-68.

50 Raff MC, Lillien LE, Richardson WD, Burne JF, Noble MD. Platelet-derived growth factor from astrocytes drives the clock that times oligodendrocyte development in culture. Nature 1988; 333: 562-565.

51 Pringle NP, Mudhar HS, Collarini EJ, Richardson WD. PDGF receptors in the rat CNS: during late neurogenesis, PDGF alpha-receptor expression appears to be restricted to glial cells of the oligodendrocyte lineage. Development 1992; 115: 535-551.

52 Nery S, Wichterle H, Fishell G. Sonic hedgehog contributes to oligodendrocyte specification in the mammalian forebrain. Development 2001; 128: 527-540.

53 Hu BY, Du ZW, Li XJ, Ayala M, Zhang SC. Human oligodendrocytes from embryonic stem cells: conserved SHH signaling networks and divergent FGF effects. Development 2009; 136: 1443-1452. 
54 Wang S, Bates J, Li X, Schanz S, Chandler-Militello D, Levine C et al. Human iPSC-derived oligodendrocyte progenitor cells can myelinate and rescue a mouse model of congenital hypomyelination. Cell Stem Cell 2013; 12: 252-264.

$55 \mathrm{Hu}$ J, Deng L, Wang X, Xu XM. Effects of extracellular matrix molecules on the growth properties of oligodendrocyte progenitor cells in vitro. J Neurosci Res 2009; 87: 2854-2862.

56 Werbowetski-Ogilvie TE, Bossé M, Stewart M, Schnerch A, Ramos-Mejia V, Rouleau $A$ et al. Characterization of human embryonic stem cells with features of neoplastic progression. Nat Biotechnol 2009; 27: 91-97.

57 Mekhail M, Almazan G, Tabrizian M. Oligodendrocyte-protection and remyelination post-spinal cord injury: a review. Prog Neurobiol 2012; 96: 322-339.

58 McTigue DM, Horner PJ, Stokes BT, Gage FH. Neurotrophin-3 and brainderived neurotrophic factor induce oligodendrocyte proliferation and myelination of regenerating axons in the contused adult rat spinal cord. J Neurosci 1998; 18: 5354-5365.

59 Ladewig J, Koch P, Brüstle O. Auto-attraction of neural precursors and their neuronal progeny impairs neuronal migration. Nat Neurosci 2014; 17: 24-26.

60 Siddiqui AM, Khazaei M, Fehlings MG. Translating mechanisms of neuroprotection, regeneration, and repair to treatment of spinal cord injury. Prog Brain Res 2015; 218: 15-54.
61 Barnabé-Heider F, Göritz C, Sabelström H, Takebayashi H, Pfrieger FW, Meletis $\mathrm{K}$ et al. Origin of new glial cells in intact and injured adult spinal cord. Cell Stem Cell 2010; 7: 470-482.

62 Kojima A, Tator $\mathrm{CH}$. Intrathecal administration of epidermal growth factor and fibroblast growth factor 2 promotes ependymal proliferation and functional recovery after spinal cord injury in adult rats. J Neurotrauma 2002; 19: 223-238.

63 Zawadzka M, Rivers LE, Fancy SP, Zhao C, Tripathi R, Jamen F et al. CNS-resident glial progenitor/stem cells produce Schwann cells as well as oligodendrocytes during repair of CNS demyelination. Cell Stem Cell 2010; 6: 578-590.

(i) (5) (2) This work is licensed under a Creative Commons Attribution-NonCommercial-ShareAlike $\quad 4.0$

International License. The images or other third party material in this article are included in the article's Creative Commons license, unless indicated otherwise in the credit line; if the material is not included under the Creative Commons license, users will need to obtain permission from the license holder to reproduce the material. To view a copy of this license, visit http:// creativecommons.org/licenses/by-nc-sa/4.0/

Supplementary Information accompanies the paper on Experimental \& Molecular Medicine website (http://www.nature.com/emm) 